\title{
Development of Fuel Usage Data Collection/Verification Technology for MRV International Regulation
}

\author{
Nam-seon Kang
}

\begin{abstract}
For greenhouse gas regulation of international marine transport, EU plans to apply MRV system to vessel entry/departure EU harbors starting 2018, and there are discussions at IMO regarding the introduction of MRV(Monitoring, Reporting, Verification) system for fuel usage in order to establish greenhouse gas regulation and ship operation and energy efficiency standards. Accordingly, this article has designed a system for greenhouse gas emission verification and improvement of ship operation data collection technology to respond to MRV regulation of EU and IMO.
\end{abstract}

Keywords-Greenhouse gas regulation, EU, IMO, MRV regulation, vessel fuel usage

\section{INTRODUCTION}

$\mathrm{E}$ U has submitted to the European Parliament the law for execution of MRV for operation data of vessel entry/departure EU harbor regadless of ship nationalities for additional regulatory for International Maritime Organization (IMO) international marine transport greenhouse gas emission, and accordingly, all ships over 5,000GT entry/departure EU harbor since January 2018 are required to measure Co2 emissions and other climate-related information every year and submit to EC with a third-party verification. Also, IMO is discussing the introduction of measurement/report/verification system for fuel usage and ship operation data in order to establish energy-efficiency standards, so it is urgent to develop technology and introduce system for response to greenhouse gas regulations on international marine transport.

Currently, however, international marine transport is experiencing ship supply surpassing harbor volume increase rate in most ship types such that supply/demand conditions are not being improved and management crisis is gradually deteriorating, and thus it is difficult to cover the additional administrative costs for technological development, system introduction, and reporting for response against MRV regulations.

Therefore, in order to improve the ship operation efficiency data collection technology and establish verification system for MRV regulation response in discussion at IMO, this study analyzes system requirements in Chapter 2, performs concept design based on such in Chapter 3 , and suggests conclusions in

Nam-seon Kang ${ }^{1}$ is with the Research institute of Medium \& Small Shipbuilding Busan, Korea.
Chapter 4.

\section{REQUIREMENT}

MRV refers to monitoring, reporting and verification, the series of process of quantifying fuel usage and operation data, improving precision through third-party verification, and reporting in the standard format. For this, it is necessary to improve the real-time ship operation data and fuel usage data collection technology and establish the system for standardized report format and qualification for verification which satisfy the international criteria for continued overall management of greenhouse gas emission and energy efficiency data.

A. Real-Time Ship Operation Data and Fuel Usage Data Collection Technology Improvements submission

There are four ways to measure the fuel usage: material balance analysis, oil tank inspection, flowmeter, and continuous measurement. Among these four, material balance analysis and oil tank stock analysis do not need additional measurement equipment to be installed, thus being preferred by marine transport companies, but it requires data to be input manually, adding to the administrative tasks of crewmen, and has high vulnerability to human error occurrence, thus increasing the costs for data verification. As for flowmeter, it needs additional measurement equipment to be installed, incurring a large cost, and finally the greenhouse gas emission measurement method through continuous measurement system requires high system implementation costs along with a large installation space and operating personnel, thus there is practical difficulty for its application to ships.

\section{B. Data Collection Automation}

Under the MRV system, the emission data per voyage/year must be measured/reported according to the approved plans, and the monitoring criteria/method require not only fuel usage and greenhouse gas emission, but also operation data including ship location and time, freight amount, task amount and such marine transport company's information, and average energy efficiency data collection in addition. The collected data is used not only independently but also in various combinations, and compared to the currently active greenhouse gas regulations, numerous data must be measured/reported, so that it is difficult to respond to the strengthened international regulations with manual input method currently in use at most marine transport 
companies.

\section{C.Report Format Standardization}

International marine transport energy efficiency and greenhouse gas reduction are not voluntary market demands but international regulations, definitely requiring a measure plan, but small/mid-sized marine transport companies significantly lack the capability for independent technology and system implementation, such that there are concerns that their market competitiveness will rapidly deteriorate as the regulations are executed, and even the large-sized marine transport companies which have implemented and been operating systems do not share a common format, so that the disparate report systems/formats are being problematized.

In order to improve such issues, this report intends to develop a method that can maximize the economic advantages of material balance analysis and oil tank stock analysis methods with low initial investment costs among the fuel consumption measurement methods and enable the data reliability security in question, and to suggest a portal system equipped with a module that can automatically convert to the standardized format using monitoring/reporting support system without individual system implementation for each marine transport company.

\section{SYSTEM DESIGN}

This study has constructed the system for ship operation efficiency data technology improvement and verification for MRV support and greenhouse gas emission reduction, which is subject to IMO regulations, and the portal system that can support marine transport companies using such has been constituted as in Figure 1.

The overall system consists of ECO Ship-Collector for ship data collection, ECO Ship-Deliver system for data transfer, ECO Ship-Manager as the greenhouse gas management portal system for marine transport company, and ship greenhouse gas and energy efficiency verification technology criteria.

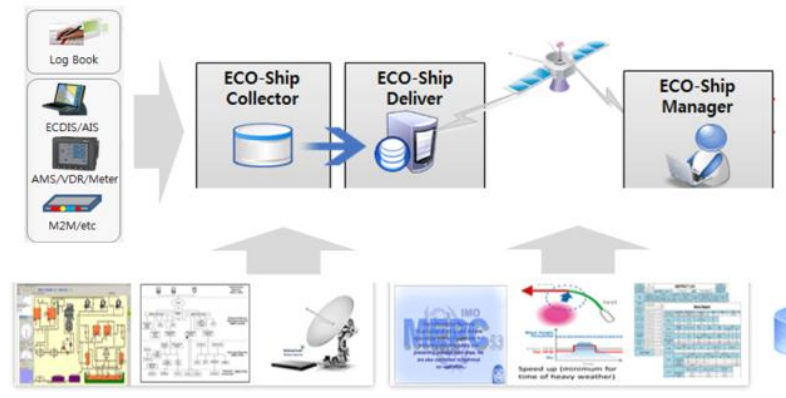

Fig. 1 Eco Ship System for MRV Regulations

\section{A. Ship Greenhouse Gas and Energy Efficiency Verification Technology Standard Development}

For the ship greenhouse gas and energy efficiency verification technology standard, the international specifications related to ship operation efficiency data MRV system being discussed at IMO shall be examined, and the system and standard for verification shall be established by securing greenhouse gas emission data through combustion gas analyzer.

\section{B. Ship Data Collection(ECO Ship-Collector)}

For ship data collection, ship energy efficiency and greenhouse gas monitoring system's data processing shall be analyzed and domestic marine transport companies' greenhouse gas data processor shall be analyzed, and for improved reliability for cross-comparison analysis verification of domestic marine transport companies' greenhouse gas data, ECDIS, AIS-based location and track data collection system has been developed, and voyage/fuel consumption data collection system based on equipment such as AMS, VDR, and flowmeter has been designed as in Figure 2.
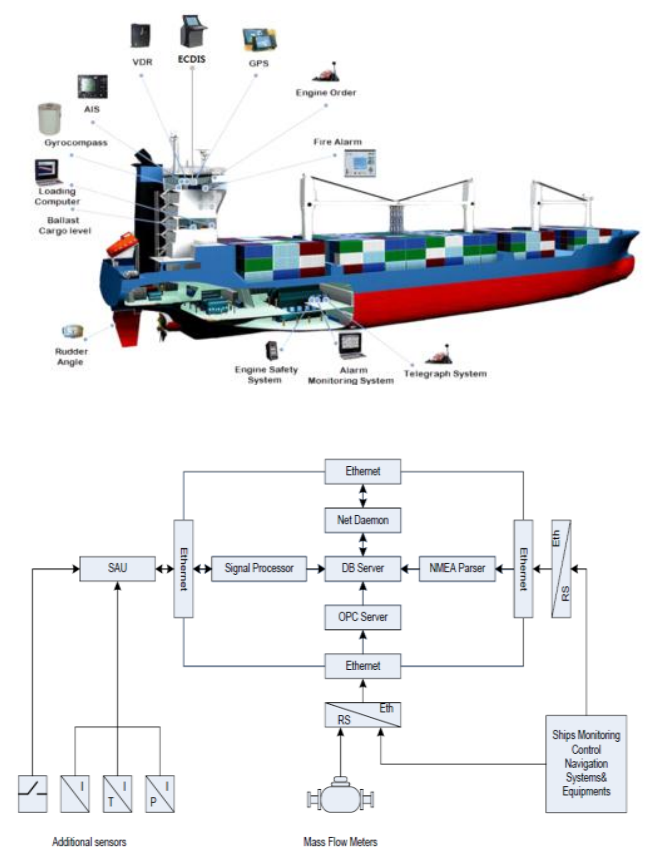

Fig. 2 ECO Ship-Collector

\section{C.Ship Data transfer(ECO Ship-Deliver)}

For real-time transfer of collected data, satellite data communication network and terminals have been analyzed to design the data communication module, and the platform for data transfer has been designed as in Figure 3. ECO Ship-Deliver enables ship operation efficiency and fuel usage data remote monitoring in IP-based satellite communication network environment, and constitutes the platform that can use protocols such as CAN-Bus, Modbus, and NMEA.

\section{Data management system(ECO SHIP-Manager)}

The greenhouse gas management portal has been designed as a system usable by marine transport company for response to IMO ship operation efficiency and MRV, allowing the management the greenhouse gas data of the marine transport company beside the ship, as shown in Figure 4. ECO Ship-Manager manages the database of the information obtained through ECO Ship-Collector and ECO Ship-Deliver and supports per-ship real-time location, voyage status information, and fuel consumption monitoring, and operates 
carbon calculator utilizing ship operation and freight information. Also, a module that can monitor $\mathrm{Co} 2, \mathrm{CH} 4, \mathrm{~N} 2 \mathrm{O}$ and such is developed so as to develop the system that can integrally manage greenhouse gas of buildings, terminals, rail, and ships of the marine transport company.

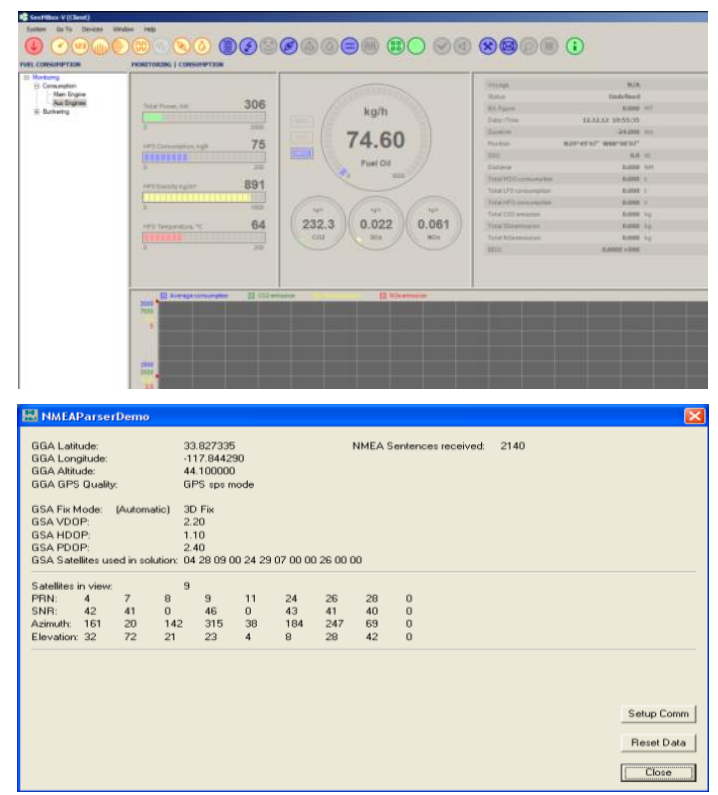

Fig. 3 ECO Ship-deliver

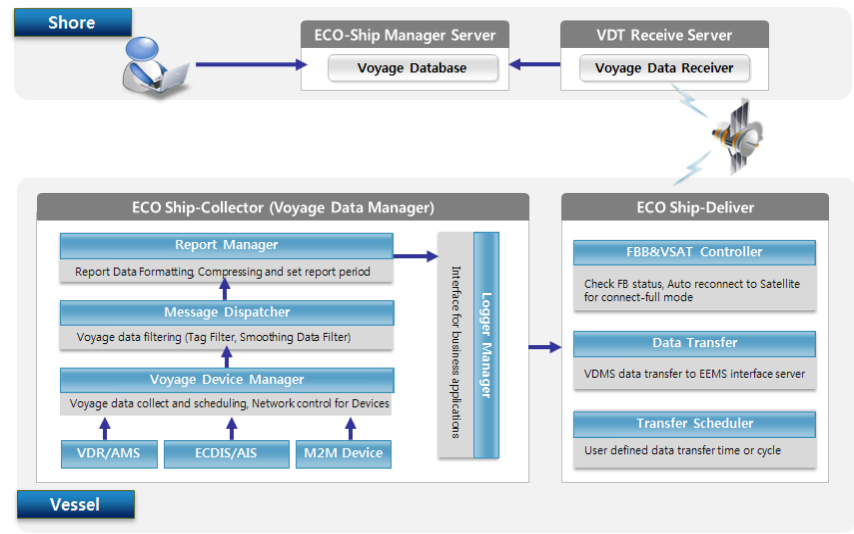

Fig. 4 ECO Ship-manager

\section{CONCLUSION}

For development of system to respond to international marine transport MRV regulations and system to verify greenhouse gas emission, it is necessary to understand the international regulations currently in discussion, and the analysis of the requirements must come first. In this article, the current status of the international marine transport MRV regulations has been analyzed, and an MRV portal system satisfying such has been designed, and the system practicality has been secured by reflecting the demands of the marine transport companies, who are the actual users.

In future studies, we intend to develop the designed ship data collection/transfer system, greenhouse gas management portal system and ship greenhouse gas and energy efficiency verification technology criteria so as to complete the system for greenhouse gas emission verification system implementation and ship operation data collection technology improvement for response to MRV regulation.

\section{ACKNOWLEDGMENT}

This study has been executed as the technology development project for maritime safety and maritime transportation infrastructure by Ministry of Oceans and Fisheries, the gratitude for which we would like to express here.

\section{REFERENCES}

[1] IMO, Guidelines for voluntary use if the ship energy efficiency operational indicator(EEOI), MEPC.1/Circ.684, IMO, August 2009.

[2] IMO, Opportunities for Reducing Greenhouse Gas Emissions from Ships, MEPC 58/INF.21, FOEI, August 2008.

[3] CORINAIR(1999), Emission inventory guidebook, European Environment Agency.

[4] IPCC(2006), 2006 IPCC Guidelines for national greenhouse gas inventories, Prepared National Greenhouse Gas Inventories Programes, Eggleston, H.S., Buendia, L., Miwa, K, Ngara, T. and Tanabe.(eds).

[5] Starcrest Consulting Group(2007ab), Maritime air emission inventory, Puget Sound Maritime Air Forum. 